\title{
Medical humanities courses becoming prerequisites in many medical schools
}

$\mathrm{S}$ hocking though it might sound to some physicians, there are those who believe that a few members of the profession have the clinical empathy of a cadaver and aren't adequately trained in the requisite observational skills needed to provide patientcentred care.

In fact, there are those who argue that medical schools and continuing medical education programs have done little to help instill something like empathic skills in those rare souls, (www.cmaj.ca /cgi/doi/10.1503/cmaj.090113).

In hopes of redressing the deficiency, an increasing number of medical schools in the United States are placing a growing emphasis on the humanities, including courses in literature and painting, as a means of teaching competencies, whether skills, knowledge or attitudes, that cannot be instilled by endlessly revisiting Dorland's Pocket Medical Dictionary. In fact, 69 of 133 accredited schools in the US now require that medical students take a course in the medical humanities, says Terri Cameron, program manager for the curriculum inventory portal at the Association of American Medical Colleges.

By contrast, while a few Canadian medical schools are making exploratory forays into medical humanities courses, those are primarily electives or if mandatory, typically have very minimal time requirements.

There is no requirement that any of the nation's 17 medical schools offer a prerequisite course in the medical humanities, Nick Busing, president of the Association of Faculties of Medicine of Canada says. But the association has urged a more diversified, flexible, competency-based curricula (www.cmaj .ca/cgi/doi/10.1503/cmaj.109-3174).

Compelled by studies demonstrating that clinical empathy can be taught through medical humanities (for example, Patient Educ Couns 2009;74:33946), American medical schools appear

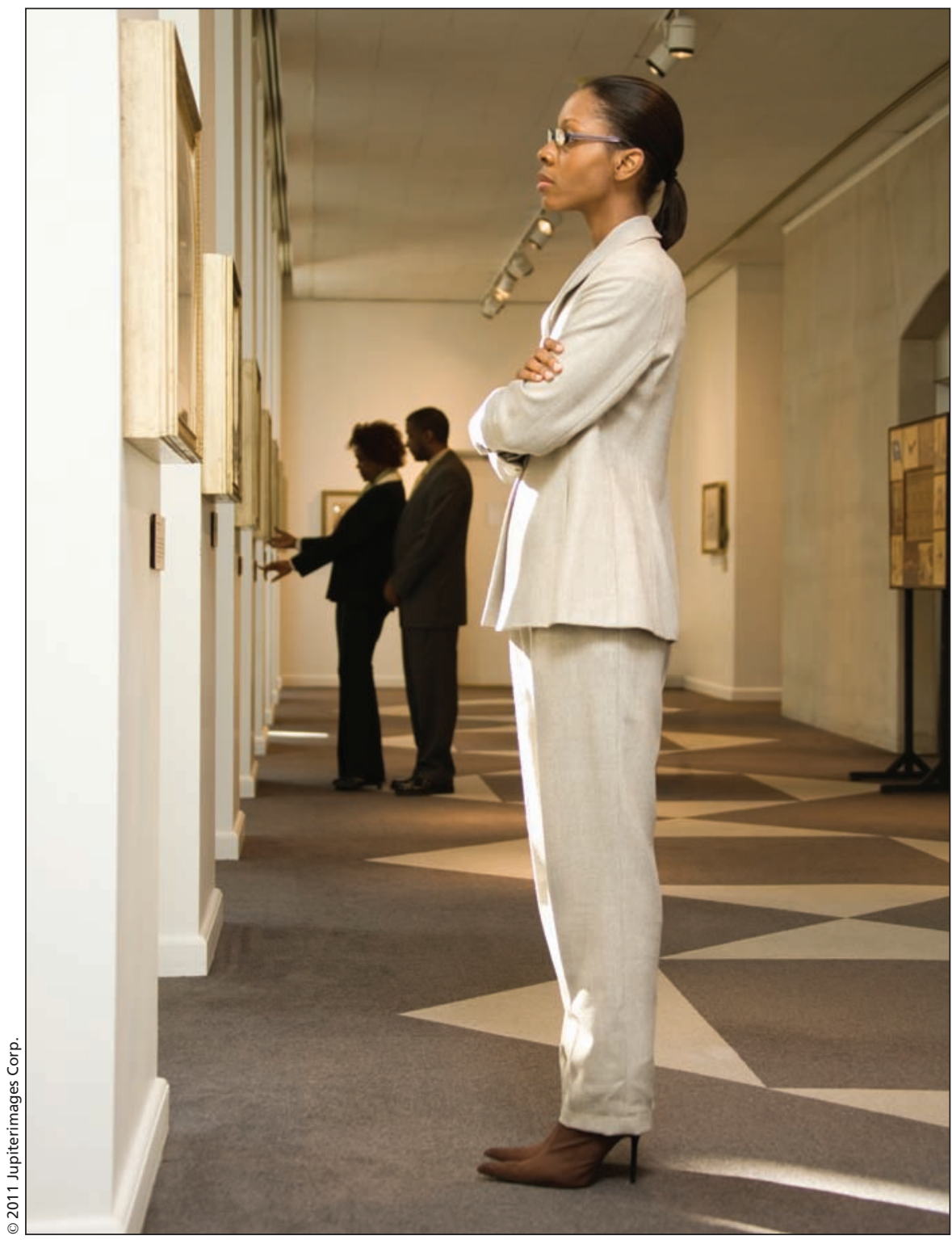

The observational skills of medical students can be improved through examining paintings and sculptures, say supporters of adding humanities courses to medical programs.

to be far more proactive in developing medical humanities courses.

The observational skills of medical students can be improved through examining paintings and sculptures, says Dr. Irwin Braverman, a medical professor at Yale University in New Haven, Connecticut and author of Medicine and Art.

To that end, Braverman also devel- oped a program called "The DoctorPatient Relationship" which brings firstyear medical students into the Yale Center for British Art to sharpen observational skills. "The thought occurred to me that if I were to show [students] an unknown object, show them something they really had no familiarity with, and ask them to describe what they saw, 
they would probably describe every single detail in that object because they didn't know what was important or unimportant. They had no prejudice or biases," he says.

Braverman soon realized that it would be beneficial to teach first-year medical students observational skills starting with a "mind that hasn't been tampered with."

That notion has since morphed into a required course which brings medical students into the museum to simply observe paintings, without interpretation. It's all about the "cerebral experience of looking at an unknown object and finding the details of this object," he says.

The value is evident from that fact that more than 24 other American medical schools, including such prestigious ones as Brown, Cornell, Duke and Stanford, have imitated or created a "slightly amplified" version, Braverman notes.

The Mount Sinai School of Medicine in New York City, New York has been another leader in the trend. It introduced an art-appreciation course for medical students in 2003, and made it a requirement for third-year students just three years later.

The program also appears to have the benefit of improving the well-being of students.

"I think that the medical school experience is so intense, it's really important to have a place where students can escape a little bit and reflect on what they're doing," says Dr. David Muller, dean for medical education and the Charles C. Morchand chair in medical education at the Mount Sinai School of Medicine.

"Nobody has data that shows that [taking humanities courses] creates one kind of doctor versus another," says Muller. "I would hope that if it accomplishes anything, it maintains the student's well-being and if it makes them a little bit more of a well-rounded person and a better clinical doctor, then that would be great."

Medical humanities courses have been slow to gain traction in Canada, although there is some evidence of movement.

But most medical schools in Canada still shy away from medical humanities, although many are now expanding admissions criteria to attract students from a range of demographic groups, Julie Clavelle, electives coordinator at the University of Ottawa faculty of medicine in Ontario, writes in an email.

Some schools, though, do have a medical humanities prerequisite, or include some medical humanities as a component of a required course.

At the University of Alberta in Edmonton, for example, first-year students are required to take a "narrative reflective practice" module which obliges them to reflect on films depicting the medical profession as part of a patient-centred care course. It allows students to "connect more fully, more deeply, with becoming a physician," says
Pamela Brett-MacLean, director of arts and humanities in health and medicine.

"We don't call it extracurricular so much, it's cocurricular; because everything that the students are involved in throughout their four years of undergraduate medical education is pertinent to their education and the kind of physician they're going to become," Brett-MacLean adds.

Similarly, at the University of Saskatchewan College of Medicine, first-year students are required to take a course in "Life Cycles and Humanities," in which they are asked to focus on issues like dealing with depression and are informed about the social conditions of Saskatoon's poor.

But while the course had a minimal time requirement of only one hour per week, "it was probably one of our least attended classes," says recent graduate Dr. Monica Miliszewski. "When you're in medicine, the science part is so overwhelming and there's so much to learn, so anything that seems like a 'feelings' class, people don't take seriously."

Miliszewski says the merits of integrating the humanities into medical school training probably weren't as apparent to some of her colleagues. "At the end of the day you have to know how to interact with people. You have to understand them, understand their fears and what goes on in their minds. You can't just treat their diseases." Adrianna Banaszek, Ottawa, Ont.

CMAJ 2011. DOI:10.1503/cmaj.109-3830 